\section{A política pública de saúde brasileira: representação e memória social de profissionais}

\author{
Brazilian National Health Policy: health \\ professionals' social representations
}

\author{
${ }^{1}$ Faculdade de Enfermagem, \\ Universidade do Estado do \\ Rio de Janeiro, Rio de Janeiro, \\ Brasil. \\ 2 Instituto de Psicologia, \\ Universidade do Estado do \\ Rio de Janeiro, Rio de Janeiro, \\ Brasil. \\ Correspondência \\ D. C. Oliveira \\ Faculdade de Enfermagem, \\ Universidade do Estado do \\ Rio de Janeiro. \\ Av. 28 de Setembro 157, \\ $7^{\circ}$ andar, Bloco $A$, \\ Rio de Janeiro, $R J$ \\ 20551-030, Brasil. \\ dcouerj@gmail.com
}

\section{Abstract}

The Brazilian Unified Health System (SUS) was created 15 years ago with the aim of promoting universal access to health care. This study analyzes the content of social representations by health professionals from Rio de Janeiro concerning the system's implementation. The study was based on social representation and social memory theory and was conducted in five health care institutions with 100 professionals. Data were collected through in-depth interviews and analyzed through lexical analysis using the Alceste 4.7 software. The results showed two thematic blocks, namely the formal and real SUS. The formal representation discusses themes related to human resources policy, health system definitions and principles, and social participation. The real representation discusses the health professional-client relationship and health care structure, hierarchical and regional organization of care, and client profile. The results reflect the main characteristics of the SUS and allow the identification of representations and memories that differentiate it from the previous system.

Health Public Policy; Health Systems; Health Personel

\author{
Denize Cristina de Oliveira ${ }^{1}$ \\ Celso Pereira de Sá 2 \\ Antonio Marcos Tosoli Gomes 1 \\ Raquel de Souza Ramos 1 \\ Noraisa Alves Pereira 1 \\ Weena Costa Rocha dos Santos 1
}

\section{Introdução}

Após 15 anos da sua implantação, o Sistema Único de Saúde (SUS) se apresenta como uma política que deve possibilitar tanto o acesso universal a cuidados básicos de saúde quanto de ponta. No entanto, sofre dificuldades associadas à insuficiência de recursos financeiros e materiais e à disparidade de salários e cargos, dentre outras. Essa realidade caracteriza uma tensão interna do sistema, que é vivenciada pelos profissionais de saúde, gerando a construção de uma forma particular de visualizar e de enfrentar tais dificuldades.

O SUS reveste-se de importância no quadro sanitário brasileiro, não somente como estrutura de organização institucional da área da saúde e modelo de atendimento à clientela, mas especialmente pela mudança impressa nas formas de direcionar, conceber, pensar e fazer a assistência à saúde no país 1 . Apesar dos avanços que o SUS alcançou na última década, coexistem ainda aspectos inovadores e conservadores desse sistema, como característica da atenção à saúde no Brasil. $\mathrm{O}$ aspecto inovador refere-se aos princípios e ao próprio perfil da proposta do sistema, bem como à qualidade dos debates e da produção intelectual do campo específico. O caráter conservador se expressa na baixa institucionalidade alcançada, entre a formulação e a execução efetiva de ações transformadoras das práticas de saúde. Percebese não haver permeabilidade entre a moderni- 
dade conceitual e legal e o conservadorismo das práticas de saúde, centradas num modelo assistencial circunscrito a respostas a demandas imediatas, medicalização da saúde e alta tecnologia de caráter hospitalocêntrico ${ }^{2}$.

Conforme discutido, a formulação do SUS envolveu uma grande participação social, conseqüentemente, mobilizando movimentos sociais, com a organização da sociedade civil em seus diversos setores de atuação (usuários, prestadores de serviço, agentes institucionais públicos, dentre outros), que se expressaram em acontecimentos concretos como a realização das Conferências Nacionais de Saúde, no acalorado debate acadêmico em torno do tema 3 .

Entre as diretrizes políticas consolidadas pela Constituição Federal no cenário nacional encontram-se os fundamentos da transformação do sistema de saúde brasileiro. A Constituição Federal de 1988 definiu a criação do SUS, que tem como princípio básico o acesso universal e igualitário às ações e serviços para a promoção, proteção e recuperação da atenção à saúde 1 . O texto constitucional expressa, ainda, uma clara intenção de deslocar o poder do centro para a periferia, tendo como o eixo central a descentralização, reforçando a autonomia municipal e a participação da comunidade. O município tem a incumbência específica de prestar serviços de atendimento à saúde da população, e à União e aos estados cabe prover a cooperação técnica e financeira 4

A plena regulamentação do SUS efetivou-se apenas em 1990 (com a aprovação das Leis $n^{\circ}$. 8.080 e $n^{\circ}$. 8.142) e sofreu vetos presidenciais importantes em diversos artigos, especialmente no que se refere aos mecanismos de transferência de recursos financeiros 4 .

Assim, o Artigo 35, parte da Lei no. 8.080, coloca-se como um ponto de partida para a construção de um sistema de financiamento que favoreça, e não dificulte, a implementação dos postulados principais do SUS. O sistema de saúde deve ser efetivado a partir de um conjunto de ações e serviços de saúde prestados por órgãos e instituições públicas Federais, Estaduais e Municipais, da administração direta e indireta e das fundações mantidas pelo poder público e, de forma complementar, pela iniciativa privada ${ }^{1}$.

Os objetivos finais do SUS se caracterizam como prestar assistência à população a partir do modelo de promoção da saúde, que implica ações buscando eliminar ou controlar as causas das doenças e agravos, ou seja, determinando ou condicionando o aparecimento de doenças; proteger a saúde da população, que consiste em ações específicas para prevenir riscos e exposições às doenças e agravos à saúde, ou seja, man- ter o seu estado de saúde; e desenvolver ações de recuperação da saúde de forma a evitar mortes e seqüelas em pessoas já acometidas por processos mórbidos.

A construção do SUS é norteada por alguns princípios doutrinários, quais sejam: a universalidade, a eqüidade e a integralidade das ações de saúde. A universalidade implica o direito ao atendimento; a eqüidade parte da premissa de que todo cidadão é igual perante o SUS e será atendido conforme as suas necessidades, permitindo a diminuição das desigualdades existentes; a integralidade implica que todas as ações de promoção, proteção e de recuperação da saúde formem um todo indivisível, que não pode ser compartimentalizado. As unidades prestadoras de serviços, com seus diversos graus de complexidade, formam também um todo indivisível, devendo configurar um sistema capaz de prestar assistência integral.

Simultaneamente, a organização do SUS é regida por cinco princípios, sendo eles: a regionalização e a hierarquização, a resolutividade, a descentralização, a complementariedade e a participação dos cidadãos. A regionalização e a hierarquização implicam que a rede de serviços do SUS deva ser organizada de forma que todas as regiões contem com serviços de saúde de diferentes níveis de atenção que se articulem a partir da sua hierarquização, permitindo um conhecimento maior dos problemas de saúde em uma área delimitada, favorecendo ações de vigilância epidemiológica, sanitária, controle de vetores e educação em saúde, além das ações de atenção ambulatorial e hospitalar em todos os níveis de complexidade; a resolutividade é definida como a exigência de que, quando um indivíduo busca o atendimento ou quando surge um problema de impacto coletivo sobre a saúde, o serviço correspondente esteja capacitado para enfrentá-lo e resolvê-lo até o nível exigido pela sua complexidade; a descentralização representa a redistribuição das responsabilidades pelas ações e serviços de saúde entre os vários níveis de governo, chegando até o nível municipal; $a$ participação dos cidadãos ou controle social, que implica a garantia constitucional de que a população, através de entidades representativas, deverá participar do processo de formulação das políticas de saúde e do controle de sua execução, em todos os níveis desde o federal até o local e, por fim, a complementariedade do setor privado está prevista quando há a necessidade de contratação de serviços privados para a complementação dos serviços públicos.

A partir das considerações traçadas, definiuse como objetivo geral desta pesquisa caracterizar e comparar os processos de constituição e 
os conteúdos das representações sociais e das memórias dos profissionais de saúde acerca da implantação do SUS, junto a instituições hospitalares, ambulatoriais e centros de saúde do $\mathrm{Mu}$ nicípio do Rio de Janeiro, buscando identificar e caracterizar as políticas de saúde efetivadas e as diferentes práticas de saúde desenvolvidas em nível municipal.

\section{Metodologia}

A pertinência da associação do referencial teórico da memória social 5,6,7 a este estudo se justifica pela importância política, econômica e estratégica do sistema de saúde para as políticas públicas no Brasil, assim como pelo tempo decorrido desde a implantação do SUS e a municipalização da saúde no Rio de Janeiro, o que possibilita a análise desse processo a partir das memórias construídas pelas instituições de saúde e pelos profissionais enquanto interlocutores institucionais 8 .

Buscar conhecer as políticas municipais e as práticas de saúde desenvolvidas nas cidades, portanto, reveste-se de importância e implica a definição de um referencial teórico que possibilite visualizar a implantação do SUS, não apenas a partir do olhar normativo-institucional, mas também a partir de diferentes pensares, que permitam retraduzir o cotidiano das relações dentro desse complexo sistema. Dessa forma, buscar acessar a memória e as representações sociais dos diferentes grupos sociais que aí interagem e, de certa forma, reconstroem o SUS no cotidiano dos serviços de saúde, pode ser um caminho profícuo para a compreensão dos aspectos psicossociais que se somam aos tantos outros elementos, resultando no sistema corporificado dos serviços de saúde.

Associada a este referencial, adotou-se também a Teoria das Representações Sociais no âmbito da psicologia social 9,10. Ressalta-se que uma representação é constituída de um conjunto de crenças, informações, opiniões e atitudes a propósito de um dado objeto social. Este conjunto de elementos se organiza, estrutura e se constitui num sistema sócio-cognitivo de tipo específico.

O desenho metodológico deste estudo envolveu cinco instituições de saúde localizadas na cidade do Rio de Janeiro constituídas há pelo menos 15 anos, de modo que tivessem construído uma história dentro do sistema de saúde brasileiro. A escolha das instituições obedeceu aos seguintes critérios de inclusão: um hospital público federal de grande porte; um hospital estadual, geral, de grande porte; um hospital municipal; um hospital privado, conveniado com o
SUS, há pelo menos 15 anos, de grande porte; e um centro de saúde de grande porte, pertencente à rede pública municipal de saúde.

Foram entrevistados cem profissionais que desenvolviam ações no âmbito das instituições selecionadas, vinte de cada instituição, que atuavam há pelo menos 15 anos. A escolha dos profissionais obedeceu aos seguintes critérios de inclusão: cinco sujeitos ocupando cargos administrativos não diretivos; cinco sujeitos ocupando postos administrativos diretivos; dez sujeitos envolvidos em atividades operacionais, cinco de nível superior e cinco de nível médio ou básico.

A coleta de dados foi realizada no primeiro semestre de 2003 com entrevistas semi-dirigidas. A análise das entrevistas foi realizada através da técnica de análise lexical mecanizada, com o uso do programa Alceste, versão 4.7 (IMAGE, Toulouse, França), que permite realizar análise do conteúdo presente no texto por meio de técnicas quantitativas de tratamento de dados textuais 11. Dessa maneira, o Alceste recorre à análise das coocorrências das palavras nos enunciados, para organizar e sumariar informações consideradas relevantes, possuindo como referência em sua base metodológica a abordagem conceitual dos "mundos lexicais" 12.

No que se refere aos aspectos éticos da pesquisa, foram respeitados os princípios da Resolução no. 196/96, do Ministério da Saúde. O projeto recebeu um parecer favorável do Comitê de Ética em Pesquisa da Universidade do Estado do Rio de Janeiro, e cada sujeito participante formalizou o seu aceite assinando o Termo de Consentimento Livre e Esclarecido.

\section{Resultados e discussão}

A apresentação dos resultados da análise das representações e memórias sociais do sistema de saúde brasileiro será realizada a partir do conjunto de dados resultantes da análise das entrevistas processadas pelo Alceste, versão 4.7, e que se referem ao conteúdo das representações.

\section{Representações e memórias do sistema de saúde brasileiro: os resultados do material discursivo}

O Alceste identificou cem Unidades de Contexto Inicial (UCI), sendo estas compatíveis com o número de entrevistas analisadas. O corpus foi dividido em 6.150 Unidades de Contexto Elementares (UCE), constituindo $100 \%$ do material disponibilizado e classificou para análise 4.583 UCE, representando $74,52 \%$ de aproveitamento do material submetido à análise. 
As 4.583 UCE foram agrupadas em seis classes lexicais, que caracterizam o conteúdo essencial presente nos textos analisados. Buscando melhor compreender o processo de divisão do conteúdo textual e a constituição das classes, o dendograma de classes (Figura 1 e Tabela 1) permite visualizar os sucessivos agrupamentos realizados, a partir da análise hierárquica descendente.

\section{Figura 1}

Dendograma de classes resultantes da análise Alceste, versão 4.7, das entrevistas dos profissionais estudados. Rio de Janeiro, Brasil, 2003.
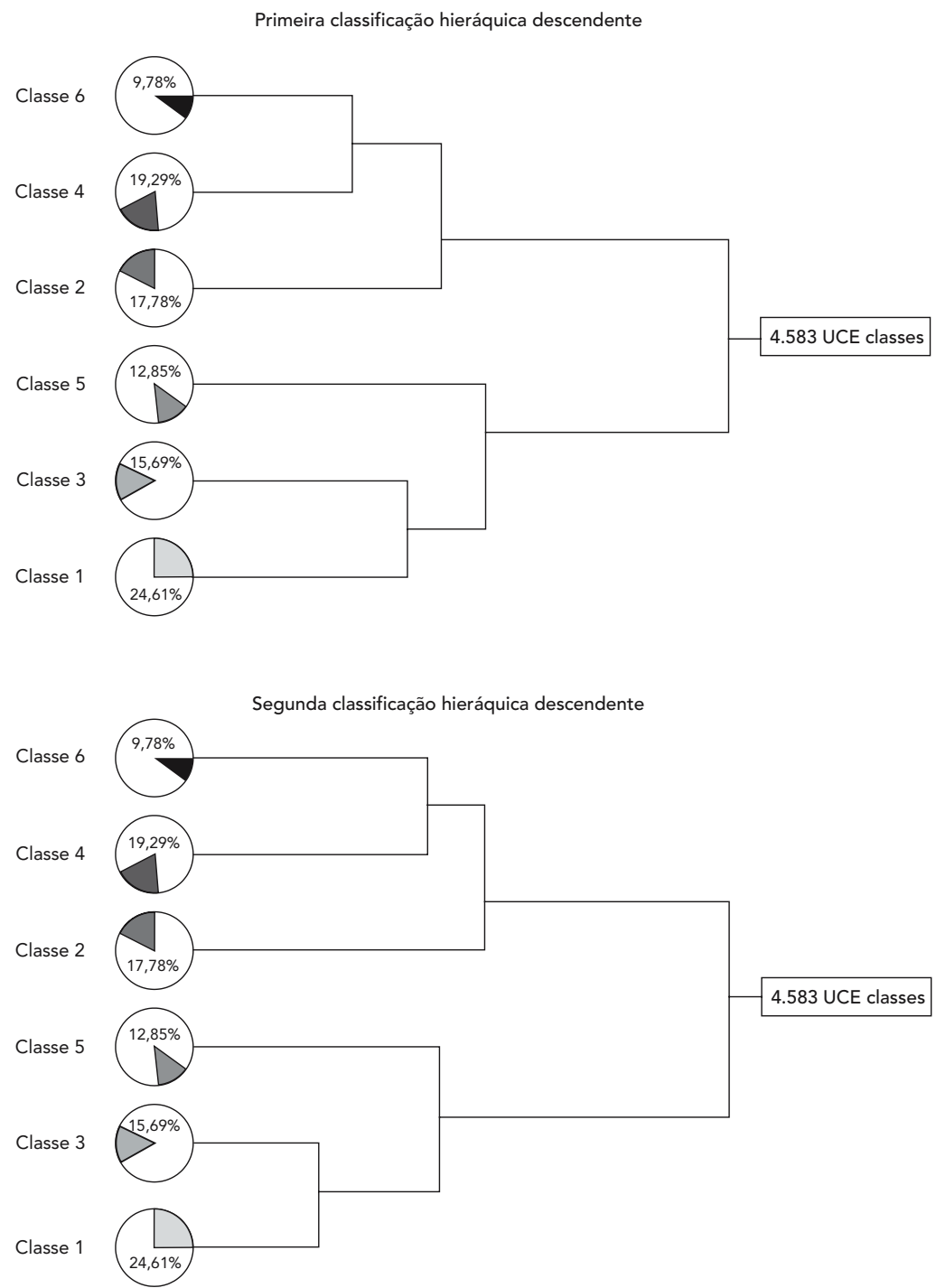

Fonte: programa Alceste, versão 4.7 (IMAGE, Toulouse, França)

UCE: Unidades de Contexto Elementares.
Observa-se que o programa dividiu as UCE em dois grandes blocos temáticos; cada um desses foi submetido a duas novas divisões; e finalmente a duas últimas. Assim, as classes 2, 4 e 6 (bloco temático 1) são resultantes, primariamente, de um bloco textual comum, o que permite inferir que elas possuem significados complementares; assim como as classes 1, 3 e 5 (bloco temático 2) são resultantes de um segundo bloco textual comum, permitindo afirmar também a existência de conteúdos comuns às mesmas. Internamente, entre os sub-conjuntos das classes 2/4/6 e 1/3/5, a relação existente é de oposição de conteúdos, já que o processo de separação das UCE busca identificar sub-grupos em função do seu grau máximo de diferenciação, processo esse repetido sucessivamente até a última classe delimitada.

Os blocos temáticos e as classes resultantes desta análise foram nomeados, de forma a expressar o conteúdo presente nos mesmos, da seguinte forma: Bloco temático 1 - A Organização do Sistema de Saúde: o SUS Formal, dentro do qual estão as classes 2 (A Política de Recursos Humanos: antes e depois do SUS); classe 4 (Definições e Princípios do Sistema de Saúde); classe 6 ( A Participação Social no SUS); e Bloco temático 2 - O Atendimento e o Acesso ao Sistema de Saúde: o SUS real, que englobou a classe 1 (A Relação Profissional-Cliente e o Atendimento: antes e depois do SUS); classe 3 (A Estrutura de Atendimento no SUS e a Hierarquização da Assistência); classe 5 (O Perfil da Clientela e o Acesso ao Atendimento: antes e depois do SUS).

Serão sumarizados, abaixo, os conteúdos formadores de cada classe, a partir dos dois blocos temáticos supracitados:

\section{- Bloco temático 1 - a organização do sistema de saúde: o SUS formal}

a) Classe 2 - a política de recursos humanos: antes e depois do SUS

Os profissionais entrevistados localizam as mudanças ocorridas na política de recursos humanos, antes e depois da implantação do SUS, em uma escala temporal, ligando-as aos quatro últimos Presidentes da República do Brasil - Fernando Collor de Mello, Itamar Franco, Fernando Henrique Cardoso e Luís Inácio Lula da Silva; além de governadores do Estado do Rio de Janeiro, como Antônio Chagas Freitas e Marcello Alencar. Essa associação a figuras políticas revela a relação de dependência das questões de recursos humanos, especialmente salários, aos dirigentes dos diferentes níveis federativos do Brasil, conforme previsto na própria lei de constituição do SUS, uma vez que os profissionais são servidores públicos 
Perfil das classes resultantes da análise Alceste, versão 4.7, das entrevistas dos profissionais estudados. Rio de Janeiro, Brasil, 2003.

\begin{tabular}{|c|c|c|c|}
\hline Bloco temático & Classes & Denominação & Composição \\
\hline \multirow[t]{3}{*}{1 - A organização do sistema de saúde: o SUS formal } & 2 & A política de recursos humanos: antes e depois do SUS & 815 UCE $(17,78 \%)$ \\
\hline & 4 & Definições e princípios do sistema de saúde & 884 UCE $(19,29 \%)$ \\
\hline & 6 & A participação social no SUS & 448 UCE $(9,78 \%)$ \\
\hline \multirow[t]{3}{*}{$\begin{array}{l}\text { 2 - O atendimento e o acesso ao sistema de saúde: } \\
\text { o SUS real }\end{array}$} & 1 & $\begin{array}{l}\text { A relação profissional-cliente e a estrutura } \\
\text { do atendimento: antes e depois do SUS }\end{array}$ & 1.128 UCE $(24,61 \%)$ \\
\hline & 3 & $\begin{array}{c}\text { A hierarquização e a regionalização da assistência } \\
\text { e a estrutura de atendimento no SUS }\end{array}$ & 719 UCE $(15,69 \%)$ \\
\hline & 5 & $\begin{array}{l}\text { O perfil da clientela e o acesso ao } \\
\text { atendimento: antes e depois do SUS }\end{array}$ & 589 UCE $(12,85 \%)$ \\
\hline
\end{tabular}

UCE: Unidades de Contexto Elementares.

com contratos firmados com os três níveis do Estado brasileiro: federal, estadual e municipal 1 .

Com relação à política de recursos humanos no período anterior ao SUS, observa-se uma tendência à idealização dos fatos do passado, refletindo um processo de formação da memória que privilegia conquistas anteriores ao sistema de saúde atual, tais como a realização de concursos públicos para ingresso de profissionais nos serviços de saúde, o maior quantitativo de servidores atuando, níveis maiores de salário, dentre outros.

No período após a implantação do SUS, observa-se referência a deteriorização salarial ocorrida ao longo da década 90; bem como o reconhecimento da adoção de incentivos ao aperfeiçoamento profissional.

A flexibilização dos vínculos trabalhistas estabelecidos pelos funcionários com as instituições públicas de saúde é referida como uma característica do atual período, em contraposição ao sistema único de contratação, característico do período anterior ao SUS. A existência de diferentes tipos de contrato de trabalho, assim como a co-existência de trabalhadores vinculados a diferentes níveis do Estado (municipal, estadual e federal), com diferentes salários e submetidos a diferentes legislações, é reconhecido como característico do período posterior ao SUS, uma vez que a hierarquização e a descentralização dos serviços exigiram mudanças nos níveis de subordinação institucional 13 .

b) Classe 4 - definiçõos e princípios do sistema de saúde

Esta classe apresenta as definições construídas pelos profissionais sobre o SUS, revelando a in- corporação dos seus princípios, das suas bases filosóficas, da sua estrutura organizacional e financeira, a partir da construção de representações. Essas representações são correlacionadas aos serviços prestados à população. Os objetivos do SUS são entendidos como facilitador da assistência à saúde e responsável pela elevação da qualidade da mesma. Os profissionais relataram uma imagem de pirâmide ao definir o SUS, valorizando o papel da rede básica de serviços de saúde na composição do sistema. Ao mesmo tempo, o SUS é entendido como um sistema universal, orientado por uma política unificada, bem como por uma proposta integrada, sendo esses dois atributos representados como pilares do sistema. Paradoxalmente, o SUS também é representado como uma proposta governamental, elaborada e implementada pelas instâncias de governo, o que revela o desconhecimento por parte dos profissionais da própria evolução histórica do sistema de saúde brasileiro, constituído a partir das Conferências Nacionais de Saúde e de ampla participação social, culminando na Constituição Federal de $1988{ }^{1}$ com a efetivação do SUS 4,14 .

Uma outra forma assumida pela representação do SUS é a de um modelo assistencial, orientado por princípios próprios. A promoção da saúde e a prevenção de doenças são referidas como objetivos do SUS, efetivada a partir de uma integração dos serviços de menor complexidade com aqueles de maior complexidade e custo (preventivos e curativos) em um único sistema. O SUS é representado, ainda, enquanto sistema que promove a integração de todas as esferas governamentais na atenção à saúde, objetivando a efetivação das suas premissas e princípios e uma maior resolutividade da assistência à saúde ${ }^{3}$. 
Os profissionais entrevistados também fazem menção às dificuldades encontradas para a implementação de alguns dos princípios do SUS, como por exemplo, a municipalização dos serviços. Para os depoentes, essas dificuldades estão associadas à estrutura dos municípios do Rio de Janeiro, que incorporaram um grande número de serviços federais durante o processo de municipalização da atenção básica.

Outros dois aspectos participantes desta representação são a estrutura organizacional e a estrutura financeira de suporte ao SUS. Quanto à estrutura organizacional, a mesma é referida às diferentes percepções sobre o processo de implantação do SUS, à supervisão do trabalho no seu interior e ao processo de descentralização das ações. A implantação do SUS é representada tanto como um processo perceptível no cotidiano dos usuários, que resulta em bom funcionamento dos serviços, quanto como algo dissociado da realidade dos serviços e sem impacto no cotidiano dos usuários. Com relação à supervisão desenvolvida dentro do sistema, observa-se um conteúdo representacional que afirma a sua não existência enquanto atividade técnica, e outro que refere a supervisão como uma atividade moderna e eficaz. A descentralização é outro aspecto participante da representação, sendo reconhecida enquanto processo de responsabilização do nível municipal e das instituições locais de atenção à saúde na prestação de assistência direta à população, mas também é observada nas relações de poder e nos recursos financeiros 15 .

Quanto à estrutura de suporte financeiro ao sistema, esta é representada a partir do repasse de recursos do Estado; da fiscalização e supervisão da utilização dos recursos; das condições e exigências para o recebimento de verbas e da autonomia financeira das unidades de saúde. Com relação à não influência da implantação do SUS na política de repasses financeiros do sistema, os sujeitos referem uma não especificidade do repasse de verbas em relação ao SUS; a descentralização dos recursos é destacada como algo discreto e que vem se processando na atualidade; no que se refere à autonomia financeira das unidades de saúde, esta é reconhecida como um fato atual, participante da estrutura do SUS 15 .

\section{c) Classe 6 - a participação social no SUS}

A participação popular e o controle social no âmbito da saúde são inovações trazidas pela Lei Orgânica da Saúde do Brasil (Lei no. 8.080/90), que instituiu o SUS e são claramente identificadas pelos sujeitos entrevistados. O controle social, para os depoentes, parece relacionar-se com o processo de conscientização acerca dos direitos constitucionais da população brasileira, daí o destaque dado à mídia e às lideranças comunitárias no interior da classe 4 .

Esse processo tem contado também com a participação dos gestores das unidades de saúde, que estão inseridos nos conselhos distritais e municipais de saúde, uma vez que nesses conselhos ganham proximidade com a população e podem melhor conhecer as suas necessidades e demandas. Este fato facilita a compreensão da sociedade organizada como possível parceira na melhoria das instituições e do sistema de saúde 4,15.

Os sujeitos destacaram, portanto, o respeito ao usuário como uma conseqüência direta desta nova organização do sistema de saúde em sua inter-relação com a sociedade. Este respeito se traduz em uma maior atenção às necessidades da população e na possibilidade desta de ser ouvida por parte das instâncias organizacionais do sistema de saúde, como as secretarias municipais, as áreas programáticas ou os próprios serviços.

Chama atenção o fato de esta classe ter sido constituída a partir da entrevistas de profissionais de dois serviços, quais sejam, o hospital federal e o centro municipal de saúde. Pode-se considerar que, com relação às demais instituições hospitalares, a problemática talvez esteja relacionada ao perfil do gestor, que determina maiores ou menores espaços de participação na gestão do serviço e, conseqüentemente, de controle social, o que demonstra uma implementação relativa do princípio de participação no interior do sistema e a sua dependência pessoal do gestor. No que tange à unidade básica de saúde (vinculada ao município), a estrutura dentro da qual este tipo de instituição se insere parece facilitar o processo, em função de o município ser o gestor direto de todo o sistema de prestação de serviços e o responsável pelo funcionamento dos conselhos de gestão nos quais ocorre é efetivada a participação popular e o controle social.

Destaca-se que a representação da participação popular e do controle social do SUS encontra-se ainda em evolução, uma vez que são processos identificados como em fase de transição entre a responsabilização unilateral das instituições e a co-responsabilização estado-sociedade civil organizada pelas dificuldades enfrentadas pelo sistema, inclusive na solicitação de recursos e de formulação e implementação de políticas e programas de atenção à saúde as autoridades governamentais 14 .

\section{- Bloco temático 2 - o atendimento e o acesso ao sistema de saúde: o SUS real}

a) Classe 1 - a relação profissional-cliente e a estrutura do atendimento: antes e depois do SUS 
Esta classe apresenta três conteúdos inter-relacionados relativos à concretização do atendimento à saúde da população, quais sejam, as condições gerais e o acesso às ações e aos serviços de saúde, a relação profissional-cliente e os determinantes do atendimento.

No que se refere às condições gerais do atendimento e ao acesso às ações e aos serviços de saúde observa-se a descrição do modo como o atendimento concretiza-se no cotidiano das instituições, especialmente em seus aspectos negativos. Foram recorrentes na discursividade dos sujeitos as dificuldades encontradas para o acesso às diversas ações e serviços, a não resolutividade de alguns serviços e o despreparo dos profissionais na execução de seu trabalho 16 .

Além desses elementos, destaca-se a não continuidade do atendimento gerando um processo de não resolução das demandas apresentadas. Os dados empíricos permitem inferir que as pessoas que já participam do sistema de saúde como usuárias encontram-se na mesma situação daquelas que ainda não se inseriram, demonstrando a falta de continuidade no atendimento à saúde, assim como as dificuldades de realização do princípio da hierarquização, gerando um estrangulamento do acesso às ações e serviços ofertados 17 .

As dificuldades apontadas para o acesso ao atendimento são explicadas pela desproporção entre a oferta e a demanda de serviços, gerando longas filas e esperas e o desgaste físico e emocional do usuário. Um outro aspecto destacado foi a existência de clientelismo na obtenção de atendimentos mais difíceis, através de relacionamentos pessoais entre profissionais de diversas instituições com o objetivo de facilitar o atendimento de amigos e familiares 17 .

A classe ainda trata, mesmo que de forma não aprofundada, da diferença estrutural de atendimento entre as instituições públicas e privadas, sendo tributado às instituições privadas condições mais adequadas para o suprimento das necessidades dos sujeitos que buscam os serviços. Ao mesmo tempo, as unidades privadas são representadas como aquelas responsáveis por atendimentos especializados e não pelo atendimento geral à saúde, o que supostamente as desresponsabilizaria do atendimento aos múltiplos agravos à saúde da população brasileira, colocando-as em situação de vantagem em termos de qualidade do atendimento.

Ainda destacando as condições nas quais o atendimento à saúde se efetiva, observa-se a menção à relação profissional-cliente. $\mathrm{O}$ modo de ação do profissional na sua relação com a clientela apresenta-se como um aspecto importante no atendimento à saúde destacado pelos profissionais, sendo a empatia o traço mais valorizado e determinante dessa relação. Nesse sentido, são ressaltadas as necessidades de olhar, de ouvir e de tocar como aspectos importantes à concretização da assistência e à construção de vínculos entre profissionais e clientes 16,17.

As memórias do antigo Instituto Nacional de Previdência Social (sistema anterior ao SUS) são representadas como de relação mecânica e impessoal, diferenciando-se do sistema atual, embora reconheçam a existência de situações negativas neste último. Considera-se que aqui se entrecruzam aspectos ligados ao sistema de saúde, bem como fatores relacionados à evolução social e tecnológica das diversas profissões da saúde e ao maior exercício do direito à informação pela clientela atendida.

Finalmente, um último aspecto determinante do atendimento é destacado, qual seja, o sentimento de insegurança do profissional. $\mathrm{O}$ atendimento de saúde à população envolve, de acordo com os depoimentos, muito desgaste físico e emocional dos profissionais. Esse desgaste apresenta-se relacionado tanto às deficiências quantitativas e de capacitação de recursos humanos, inerentes às unidades de saúde, quanto à exposição pública dos profissionais gerando situações constrangedoras e até mesmo violentas.

Com relação às unidades, ressalta-se a ausência de recursos humanos adequados, o que leva os profissionais a desenvolverem estratégias alternativas para que a execução do trabalho. Além disso, a sensação de insegurança, especialmente em unidades de emergência, mantém-se presente em função da ausência de uma política institucional específica para este fim. Outro aspecto gerador de insegurança refere-se às relações estabelecidas com os diferentes usuários, nas quais o "tratar bem" relaciona-se muito mais ao medo de possíveis represálias externas (oriundas de pessoas envolvidas com a criminalidade), do que à efetivação de um direito dos cidadãos.

b) Classe 3 - a hierarquização e a regionalização da assistência e a estrutura de atendimento no SUS

Os conteúdos desta classe se referem aos significados construídos em torno dos princípios de hierarquização e de regionalização da assistência prestada, permeados pelo sistema de referência e contra-referência operado entre as unidades de saúde participantes do sistema.

Os profissionais entrevistados se posicionam positivamente frente ao princípio de regionalização da assistência à saúde, segundo o qual os serviços devem atender a sua população circunvizinha, e apenas quando a complexidade do caso o exigir, poderá ser encaminhado pelo profissional 
de saúde para outro serviço, fora da região de moradia do usuário. No entanto, os profissionais afirmam que esse princípio não é respeitado, o que resulta em excesso de demanda aos serviços especializados e mais bem conceituados, especialmente aqueles que atendem emergências. Esse é um dos problemas principais apontados para a organização da assistência no SUS, na atualidade, e que teve início com a sua implantação, já que no sistema anterior a orientação da demanda era feita pelo acesso exclusivo de pessoas detentoras do direito de atendimento em determinadas unidades de saúde 18 .

O segundo princípio destacado pelos profissionais foi o de hierarquização da assistência, que implica na existência de uma organização dos serviços em forma de pirâmide, na qual os serviços devem atender a uma demanda específica, segundo o grau de complexidade das ações oferecidas. O funcionamento desse sistema hierarquizado deveria ocorrer através do encaminhamento, pelo profissional de saúde, de clientes de um nível de assistência para outro, segundo a necessidade do usuário 19.

No entanto, os profissionais afirmam que esse princípio não é respeitado, uma vez que o atendimento de emergência é utilizado para resolver todas as queixas que, por dificuldade ou falta de acesso, não são atendidas nos outros níveis de assistência. Ou seja, o cliente faz uso do sistema segundo as suas necessidades, encontrando formas de burlar a organização pré-definida dos serviços. Reconhecem, portanto, que as atribuições dos serviços são específicas e hierarquizadas, mas a sua utilização é indevida.

Observa-se nas representações profissionais uma atitude crítica frente à universalização do acesso à saúde, associando a ela as dificuldades de efetivação dos dois princípios apresentados, e também do longo tempo de espera enfrentado pelos clientes para a obtenção dos atendimentos especializados ou de maior complexidade. Nesse aspecto, observa-se nas representações profissionais uma tentativa de definição do que é ou não lícito para o atendimento à saúde.

Um último aspecto apontado pelos entrevistados refere-se a uma percepção de aumento da complexidade das demandas após a implantação do SUS, sendo que para alguns esse fato se associa à universalização da assistência e, para outros, a uma mudança no perfil epidemiológico da população brasileira.

c) Classe 5 - o perfil da clientela e o acesso ao atendimento: antes e depois do SUS

Esta classe apresenta um conteúdo acerca do perfil e do acesso da clientela às unidades e aos serviços de saúde oferecidos, realizando uma comparação desse acesso antes e depois da implantação do SUS.

Na representação dos entrevistados, o princípio da universalização do atendimento é uma realidade no sistema de saúde atual, no qual qualquer cidadão brasileiro pode receber atenção à saúde na rede pública e conveniada de serviços de saúde participantes do SUS. Os profissionais fazem um paralelo com os sistemas anteriores, nos quais qualquer atendimento de saúde era condicionado à vinculação do cliente a algum instituto previdenciário 1,4,20.

Essa universalização da assistência, ponto central na proposta do sistema de saúde brasileiro atual, observada a partir da implantação do SUS, resultou em aumento quantitativo dos atendimentos e em mudanças no perfil dos clientes que buscam os serviços. Parte dos profissionais representa a clientela na atualidade como mais consciente dos seus direitos de acesso aos serviços e ações de saúde. O perfil da clientela apresenta-se como uma característica específica de cada unidade, ou seja, os sujeitos apontam uma pauperização dos sujeitos atendidos no hospital e uma elevação do nível sócio-econômico da clientela dos serviços da rede básica 21 .

Observa-se, dessa forma, que o sistema de saúde brasileiro veio atender as necessidades de uma parcela significativa da população, não apenas daquela excluída no sistema anterior, mas também dos trabalhadores urbanos e rurais, da classe média e também da burguesia, naqueles serviços de maior custo 22 . Os resultados desta análise ainda evidenciam aspectos da organização formal do sistema de saúde e da sua existência legal, revelando uma imagem do texto legal caracterizada pela dissociação em relação às práticas observadas nos serviços de saúde.

\section{Conclusões}

Os resultados discutidos refletem as principais características e dificuldades do sistema de saúde brasileiro, tais como os recursos humanos, o financiamento, as condições do atendimento da população, a participação e o acesso da clientela ao sistema; bem como um conhecimento fragmentado dos princípios que regem o SUS pelo grupo estudado. A dimensão das atitudes, presente na representação, revela dois posicionamentos distintos: um negativo referido às dificuldades enfrentadas para a implantação do SUS; e outro positivo relativo aos direitos assegurados pelo novo sistema.

Com relação aos recursos humanos, ressaltase a convivência, em uma mesma unidade, de 
profissionais com vínculos distintos (municipal, estadual e federal), salários e direitos trabalhistas diferentes e com particularidades, fato tido como empecilho à constituição de uma equipe multidisciplinar integrada. Quanto ao financiamento, o SUS parece ter trazido mudanças no acesso aos recursos e na transparência de sua origem e destino.

$\mathrm{O}$ acesso universal às ações e serviços foi o princípio do SUS melhor explicitado pelos profissionais, sendo também identificado como o aspecto diferencial mais importante em relação ao modelo assistencial anterior. Ao mesmo tempo, na representação profissional, a clientela atendida nos hospitais vem apresentando características de pauperização, ao passo que nas unidades básicas de saúde observa-se elevação do nível sócio-econômico dos usuários. Considerando que a construção de uma representação implica a incorporação de diversos elementos, tais como conhecimentos relativos aos objetivos do SUS, aos seus princípios e a sua dinâmica interna, mas também implica um posicionamento diante dele, aceitando-o ou não.

Os resultados permitem visualizar elementos representacionais do sistema de saúde brasileiro, conforme concebido pelos profissionais de saúde, tais como os recursos humanos, o finan- ciamento, a participação da população, dentre outros, além de permitir vislumbrar o posicionamento dos sujeitos frente às condições do atendimento à saúde, ao acesso da clientela ao sistema, revelando um conhecimento fragmentado dos objetivos e princípios que regem o SUS; uma atitude negativa frente às dificuldades do sistema; uma atitude positiva frente aos direitos assegurados pelo novo sistema; uma imagem de pirâmide, condizente com o princípio de hierarquização da atenção.

Conclui-se que o SUS, ao longo dos 15 anos de implantação, vem permitindo a formação de representações sociais entre os profissionais, que o identificam como um sistema de atenção à saúde diferente do anterior. O conteúdo da representação reflete os princípios propostos nos documentos de sua constituição, o que reflete a incorporação dos mesmos. No entanto, essa incorporação não vem se dando de forma naturalizada, mas vem despertando posicionamentos por parte dos profissionais de saúde sobre a própria pertinência desses novos princípios da atenção pública à saúde ao contexto atual brasileiro. Pode-se levantar a hipótese de que a representação social do SUS está em processo de formação ou transformação, considerando as múltiplas tensões observadas nos conteúdos analisados.

\section{Resumo}

A política pública brasileira de saúde, conhecida como Sistema Único de Saúde (SUS), foi criada há 15 anos, objetivando prover o acesso universal aos cuidados de saúde. Este trabalho objetiva caracterizar o conteúdo das representações sociais construídas pelos profissionais de saúde sobre a implantação do SUS, na cidade do Rio de Janeiro. Ele foi embasado na Teoria de Representação e Memória Social. O estudo foi desenvolvido em cinco instituições de saúde com cem profissionais. Os dados foram coletados através de entrevistas em profundidade e analisados através da análise lexical com o uso do programa Alceste, versão 4.7. Os resultados apontaram dois blocos temáticos, o SUS formal e o real. O primeiro compreende as temáticas relacionadas à política de recursos humanos, às definições e princípios do sistema de saúde e à participação social. O segundo abarca a relação profissional-cliente e a estrutura do atendimento, a hierarquização e a regionalização da assistência e a estrutura do atendimento e o perfil da clientela. Os resultados refletem as principais características do sistema e permitem identificar representações e memórias que o diferencia do anterior.

Políticas Públicas de Saúde; Sistemas de Saúde; Pessoal de Saúde

\section{Colaboradores}

Todos os autores participaram do processo de pesquisa em diferentes fases, da discussão dos dados e da concepção e elaboração do artigo. A. M. T. Gomes organizou e redigiu a análise dos dados. N. A. Pereira, R. S. Ramos e W. C. R. Santos redigiram a revisão sobre o histórico da legislação do sistema de saúde. D. C. Oliveira e C. P. Sá descreveram a metodologia, elaboraram as figuras e realizaram a análise estatística textual. O manuscrito foi revisado pelos três primeiros autores para sua redação final. 


\section{Referências}

1. Brasil. Constituição da República Federativa do Brasil, 5 de outubro de 1988. São Paulo: Editora Atlas; 1991.

2. Campos GWS. Análise crítica das contribuições da saúde coletiva à organização das práticas de saúde no SUS. In: Fleury S, organizador. Saúde e democracia: a luta do CEBES. São Paulo: Lemos Editorial; 1997. p. 113-24.

3. Ministério da Saúde. Conferência Nacional de Saúde 8a. In: Anais da 8a Conferência Nacional de Saúde. Brasília: Centro de Documentação Ministério da Saúde; 1987

4. Brasil. Lei Orgânica de Saúde no. 8.080, de 19 de setembro de 1990. Dispõe sobre as condições para a promoção, proteção e recuperação de saúde, a organização e o funcionamento dos serviços correspondentes e da outras providencias. Diário Oficial da União 1990; 20 set.

5. Halbwachs M. Les cadres sociaux de la mémoire. Paris: Albin Michel; 1994

6. Le Goff J. Histoire et mémoire. Paris: Gallimard; 1988.

7. Sá CP. As memórias da memória social. In: Sá CP, organizador. Memória, imaginário e representações sociais. Rio de Janeiro: Editora Museu da República; 2005. p. 63-86.

8. Cardoso MHCA, Gomes R. Representações sociais e história: referenciais teórico-metodológicos para o campo da saúde coletiva. Cad Saúde Pública 2000; 2:499-506.

9. Moscovici S. La psychanalyse, son image et son public. Paris: PUF; 1976.

10. Jodelet D. Représentations sociales: un domaine en expansion. In: Jodelet D, editor. Les représentations sociales. Paris: Presses Universitaires de France; 1989. p. 47-78.

11. Reinert M. Alceste, une méthodologie d'analyse des dones textualles et une application: Aurelia de G. De Nerval. Bull Méthodol Sociol 1990; 26:24-54.

12. Oliveira DC, Gomes AMT, Marques SC. Análise estatística de dados textuais na pesquisa das representações sociais: alguns princípios e uma aplicação ao campo da saúde. In: Menin MSS, Shimizu AM, organizadoras. Experiência e representação social: questões teóricas e metodológicas. São Paulo: Casa do Psicólogo; 2005. p. 157-200.
13. Aguilera CE, Bahia LA. História das políticas de saúde no Brasil. In: Aguilera CE, Bahia LA, organizadores. Temas de políticas de saúde. Rio de Janeiro: Universidade Federal do Rio de Janeiro; 1993. p. 3-13.

14. Cordeiro H. Descentralização, universalidade e eqüidade nas reformas da saúde. Ciênc Saúde Coletiva 2001; 6:319-28.

15. Brasil. Norma Operacional Básica do Sistema Único de Saúde - NOB SUS 01/96. Diário Oficial da União 1996; 6 nov.

16. Fernandes JCL. A quem interessa a relação médico paciente? Cad Saúde Pública 1993; 9:21-7.

17. Traverso-Yepez M, Morais NA. Reivindicando a subjetividade dos usuários da Rede Básica de Saúde: para uma humanização do atendimento. Cad Saúde Pública 2004; 20:80-8.

18. Teixeira CF. Promoção e vigilância da saúde no contexto da regionalização da assistência à saúde no SUS. Cad Saúde Pública 2002; 8 Suppl 1:S15362.

19. Gil CRR. Atenção primária, atenção básica e saúde da família: sinergias e singularidades do contexto brasileiro. Cad Saúde Pública 2006; 22:1171-81.

20. Hartz ZMA, Contandriopoulos AP. Integralidade da atenção e integração de serviços de saúde: desafios para avaliar a implantação de um "sistema sem muros”. Cad Saúde Pública 2004; 20 Suppl 2: S331-6.

21. Carvalho MS, D'Orsi E, Prates EC, Toschi WDM, Shiraiwa T, Campos TP, et al. Demanda ambulatorial em três serviços da rede pública do município do Rio de Janeiro, Brasil. Cad Saúde Pública 1994; 10:17-29.

22. Oliveira EXG, Travassos C, Carvalho MS. Acesso à internação hospitalar nos municípios brasileiros em 2000: territórios do Sistema Único de Saúde. Cad Saúde Pública 2004; 20 Suppl 2:S298-309.

Recebido em 11/Ago/2006

Aprovado em 05/Jun/2007 